\title{
Vitamin A supplementation and BCG vaccination at birth in low birthweight neonates: two by two factorial randomised controlled trial
}

\author{
Christine Stabell Benn, senior researcher, ${ }^{1,2}$ Ane Bærent Fisker, clinician, ${ }^{2}$ Bitiguida Mutna Napirna, \\ obstetrician, ${ }^{3}$ Adam Roth, clinician, , ${ }^{4}$ Birgitte Rode Diness, clinician, ${ }^{2}$ Karen Rokkedal Lausch, clinician, ${ }^{2}$ Henrik \\ Ravn, senior statistician, ${ }^{1}$ Maria Yazdanbakhsh, professor, ${ }^{5}$ Amabelia Rodrigues, research director , ${ }^{2}$ Hilton \\ Whittle, professor, ${ }^{6}$ Peter Aaby, professor $^{1,2}$
}

${ }^{1}$ Bandim Health Project, Statens Serum Institut, Copenhagen, Denmark

${ }^{2}$ Bandim Health Project, Indepth Network, Bissau, Guinea-Bissau

${ }^{3}$ Maternidade, Hospital Nacional Simão Mendes, Bissau, GuineaBissau

${ }^{4}$ Department of Medical Microbiology, Lund University, Malmö, Sweden

${ }^{5}$ Department of Parasitology, Leiden University, Leiden, Netherlands

${ }^{6}$ The MRC Laboratories, Fajara, POB 273, Gambia

Correspondence to: C S Benn, Bandim Health Project, Statens Serum Institut, Artillerivej 5, 2300 CopenhagenS, Denmarkcb@ssi.dk

Cite this as: BMJ 2010;340:c1101 doi:10.1136/bmj.c1101

\section{ABSTRACT}

Objective To investigate the effect of vitamin A supplementation and BCG vaccination at birth in low birthweight neonates.

Design Randomised, placebo controlled, two by two factorial trial.

Setting Bissau, Guinea-Bissau.

Participants 1717 low birthweight neonates born at the national hospital.

Intervention Neonates who weighed less than $2.5 \mathrm{~kg}$ were randomly assigned to $25000 \mathrm{IU}$ vitamin A or placebo, as well as to early BCG vaccine or the usual late BCG vaccine, and were followed until age 12 months.

Main outcome measure Mortality, calculated as mortality rate ratios (MRRs), after follow-up to 12 months of age for infants who received vitamin A supplementation compared with those who received placebo.

Results No interaction was observed between vitamin A supplementation and $B C G$ vaccine allocation $(P=0.73)$.

Vitamin A supplementation at birth was not significantly associated with mortality: the MRR of vitamin A supplementation compared with placebo, controlled for randomisation to "early BCG" versus "no early BCG" was 1.08 (95\% Cl 0.79 to 1.47 ). Stratification by sex revealed a significant interaction between vitamin $A$ supplementation and $\operatorname{sex}(P=0.046)$, the MRR of vitamin $A$ supplementation being $0.74(95 \% \mathrm{Cl} 0.45$ to 1.22$)$ in boys and 1.42 (95\% Cl 0.94 to 2.15$)$ in girls. When these data were combined with data from a complementary trial among normal birthweight neonates in Guinea-Bissau, the combined estimate of the effect of neonatal vitamin $A$ supplementation on mortality was $1.08(95 \% \mathrm{Cl} 0.87$ to 1.33); 0.80 (95\% Cl 0.58 to 1.10$)$ in boys and 1.41 (95\% $\mathrm{Cl} 1.04$ to 1.90$)$ in girls ( $\mathrm{P}=0.01$ for interaction between neonatal vitamin $\mathrm{A}$ and sex).

Conclusions The combined results of this trial and the complementary trial among normal birthweight neonates have now shown that, overall, it would not be beneficial to implement a neonatal vitamin A supplementation policy in Guinea-Bissau. Worryingly, the trials show that vitamin A supplementation at birth can be harmful in girls.
Previous studies and future trials should investigate the possibility that vitamin A supplementation has sex differential effects.

Trial registration ClinicalTrials.gov NCT00168610.

\section{INTRODUCTION}

Vitamin A deficiency is widespread in low income countries. Vitamin A supplementation to children aged 6 months or more has been associated with significant reductions in overall mortality. ${ }^{1}$ To date, six trials testing the effect of neonatal vitamin A supplementation on mortality have been conducted. Three trials, all conducted in Asia, have shown that neonatal vitamin A supplementation has a beneficial effect on mortality. ${ }^{2-4}$ Three trials, two conducted in Africa and one small trial from Nepal, found no beneficial effect. ${ }^{5-8}$ Some groups have advocated that neonatal vitamin A supplementation be made policy in South Asia. ${ }^{49}$ Other groups, including our own, have found no justification for initiating comprehensive neonatal vitamin A supplementation. ${ }^{10-13}$ As such, an important debate regarding the potential policy implications is ongoing.

The population of Guinea-Bissau is classified by the World Health Organization as having moderate to severe vitamin A deficiency. ${ }^{14}$ Since 2001, Guinea-Bissau has conducted regular national vitamin A campaigns during which children between 6 months and 5 years of age were offered vitamin A supplementation.

We conducted a trial of neonatal vitamin A supplementation trial in Guinea-Bissau in 2002-2005, in which we randomly assigned newborns of normal birth weight to receive 50000 IU vitamin A or placebo together with the BCG vaccine. ${ }^{7}$ A total of $27 \%$ of the children in this trial were vitamin A deficient (corresponding to a retinol level below $0.7 \mu \mathrm{mol} / \mathrm{l}$ ) at 6 weeks of age and $9 \%$ were deficient at 4 months of age. ${ }^{15}$ One mother $(<1 \%)$ was deficient. Neonatal vitamin A supplementation tended to reduce mortality in boys; however, it tended to be associated with increased mortality in girls, particularly when the 
Table 1|Baseline characteristics of low birthweight children who received vitamin A supplementation or placebo at birth

\begin{tabular}{|c|c|c|c|c|c|c|}
\hline & \multicolumn{2}{|c|}{ All $(n=1717)$} & \multicolumn{2}{|c|}{ Boys $(n=758)$} & \multicolumn{2}{|c|}{ Girls ( $n=959)$} \\
\hline & $\begin{array}{c}\text { Vitamin } A \\
\text { supplementation } \\
(n=854)\end{array}$ & $\begin{array}{l}\text { Placebo } \\
(n=863)\end{array}$ & $\begin{array}{c}\text { Vitamin A } \\
\text { supplementation } \\
(n=362)\end{array}$ & $\begin{array}{l}\text { Placebo } \\
(n=396)\end{array}$ & $\begin{array}{c}\text { Vitamin } A \\
\text { supplementation } \\
(n=492)\end{array}$ & $\begin{array}{l}\text { Placebo } \\
(n=467)\end{array}$ \\
\hline $\begin{array}{l}\text { Median maternal mid upper arm circumference } \\
\text { (mm; 10th to 90th centiles) }\end{array}$ & $\begin{array}{c}232 \\
\text { (208 to } 274)\end{array}$ & $\begin{array}{c}232 \\
(206 \text { to } 274)\end{array}$ & $\begin{array}{c}238 \\
(208 \text { to } 271)\end{array}$ & $\begin{array}{c}232 \\
(208 \text { to } 274)\end{array}$ & $\begin{array}{c}232 \\
(208 \text { to } 274)\end{array}$ & $\begin{array}{c}232 \\
(202 \text { to } 280)\end{array}$ \\
\hline Median age at enrolment (days; 10 th to 90th centiles) & $\begin{array}{c}1 \\
(1 \text { to } 9)\end{array}$ & $\begin{array}{c}1 \\
(1 \text { to } 9)\end{array}$ & $\begin{array}{c}2 \\
(1 \text { to } 9)\end{array}$ & $\begin{array}{c}1 \\
\text { (1 to } 9)\end{array}$ & $\begin{array}{c}1 \\
\text { (1 to } 9)\end{array}$ & $\begin{array}{c}1 \\
\text { (1 to } 9)\end{array}$ \\
\hline Median Ballard score (10th to 90th centiles) & $\begin{array}{c}38 \\
(26 \text { to } 42)\end{array}$ & $\begin{array}{c}38 \\
(27 \text { to } 42)\end{array}$ & $\begin{array}{c}38 \\
(26 \text { to } 42)\end{array}$ & $\begin{array}{c}38 \\
(28 \text { to } 42)\end{array}$ & $\begin{array}{c}38 \\
(27 \text { to } 42)\end{array}$ & $\begin{array}{c}37 \\
(26 \text { to } 42)\end{array}$ \\
\hline Median weight at enrolment (kg; 10th to 90th centiles) & $\begin{array}{c}2.12 \\
(1.59 \text { to } 2.36)\end{array}$ & $\begin{array}{c}2.16 \\
(1.60 \text { to } 2.38)\end{array}$ & $\begin{array}{c}2.11 \\
(1.63 \text { to } 2.36)\end{array}$ & $\begin{array}{c}2.17 \\
\text { (1.65 to } 2.38)\end{array}$ & $\begin{array}{c}2.14 \\
(1.56 \text { to } 2.36)\end{array}$ & $\begin{array}{c}2.16 \\
\text { (1.52 to } 2.38)\end{array}$ \\
\hline Median length (cm; 10th to 90th centiles) & $\begin{array}{c}45 \\
(42 \text { to } 47)\end{array}$ & $\begin{array}{c}45 \\
(42 \text { to } 47)\end{array}$ & $\begin{array}{c}45 \\
(42 \text { to } 47)\end{array}$ & $\begin{array}{c}45 \\
(42 \text { to } 47)\end{array}$ & $\begin{array}{c}45 \\
(42 \text { to } 47)\end{array}$ & $\begin{array}{c}45 \\
(42 \text { to } 47)\end{array}$ \\
\hline $\begin{array}{l}\text { Median mid upper arm circumference } \\
\text { (mm; 10th to 90th centiles) }\end{array}$ & $\begin{array}{c}76 \\
(64 \text { to } 88)\end{array}$ & $\begin{array}{c}76 \\
(64 \text { to } 88)\end{array}$ & $\begin{array}{c}76 \\
(64 \text { to } 88)\end{array}$ & $\begin{array}{c}76 \\
\text { (64 to } 88)\end{array}$ & $\begin{array}{c}76 \\
(64 \text { to } 88)\end{array}$ & $\begin{array}{c}76 \\
(64 \text { to } 88)\end{array}$ \\
\hline Median head circumference ( $\mathrm{cm} ; 10$ th to 90 th centiles) & $\begin{array}{c}30.5 \\
(28.0 \text { to } 33.0)\end{array}$ & $\begin{array}{c}31.0 \\
(28.0 \text { to } 33.0)\end{array}$ & $\begin{array}{c}31.0 \\
(28.0 \text { to } 33.0)\end{array}$ & $\begin{array}{c}31.0 \\
(28.5 \text { to } 33.0)\end{array}$ & $\begin{array}{c}30.5 \\
(28.0 \text { to } 32.5) \\
\end{array}$ & $\begin{array}{c}30.5 \\
(28.0 \text { to } 32.5)\end{array}$ \\
\hline $\begin{array}{l}\text { Median abdominal circumference } \\
\text { (cm; 10th to 90th centiles) }\end{array}$ & $\begin{array}{c}25.5 \\
(23.0 \text { to } 28.0)\end{array}$ & $\begin{array}{c}25.5 \\
\text { (23.0 to } 28.0)\end{array}$ & $\begin{array}{c}25.5 \\
\text { (23.0 to } 28.0)\end{array}$ & $\begin{array}{c}25.0 \\
\text { (23.0 to } 28.0)\end{array}$ & $\begin{array}{c}25.5 \\
\text { (23.0 to } 28.0)\end{array}$ & $\begin{array}{c}26.0 \\
\text { (23.0 to } 28.5)\end{array}$ \\
\hline Had twin or triplet enrolled in the trial (n (\%)) & $137(16)$ & $137(15)$ & $63(17)$ & $52(13)$ & $74(15)$ & $85(18)$ \\
\hline Mother dead at enrolment (n (\%)) & $5(1)$ & $1(0)$ & $2(1)$ & $0(0)$ & $3(1)$ & $1(0)$ \\
\hline From Bandim Health Project study area (n (\%)) & $214(25)$ & $196(23)$ & $94(26)$ & $89(22)$ & $120(24)$ & $107(23)$ \\
\hline Did not receive oral polio vaccine at birth (n (\%)) & $42(5)$ & $51(6)$ & $13(4)$ & $23(6)$ & $29(6)$ & $28(6)$ \\
\hline Allocated to "early BCG" (n (\%)) & $431(50)$ & $431(50)$ & $181(50)$ & $197(50)$ & $250(51)$ & $234(50)$ \\
\hline
\end{tabular}

girls started receiving the diphtheria-tetanus-pertussis (DTP) vaccine recommended at 6,10 , and 14 weeks of age. ${ }^{16}$ It has been suggested ${ }^{1718}$ that the lack of benefit of vitamin A in our trial could potentially be the result of the exclusion of low birthweight newborns, because such children would be more likely be deficient in vitamin A than children of normal birth weight. However, this exclusion criterion would not explain the sex differential effects in boys and girls and the fact that the negative effect in girls coincided with DTP vaccination.

In parallel with the trial among normal birthweight infants, we also conducted a trial among low birthweight newborns. Low birthweight infants were randomly allocated in a two by two factorial design to early BCG vaccination or the usual delayed BCG vaccination and to $25000 \mathrm{IU}$ vitamin A or placebo. We had hypothesised a priori that vitamin A supplementation would be particularly beneficial when provided with the BCG vaccine, but for financial reasons and owing to the limited number of low birthweight newborns, the study was only powered to look for the effects of vitamin A regardless of BCG allocation.

We found no evidence for interaction between vitamin A supplementation and BCG vaccination; therefore, we chose to present the results of the two interventions in two separate papers. The "early BCG" versus "no early BCG" part of the trial will be presented elsewhere. This paper presents the effects of neonatal vitamin A supplementation at birth on infant mortality among low birthweight newborns in urban Guinea-Bissau. Furthermore, it presents the results of a combined analysis of the two neonatal vitamin A trials from Guinea-Bissau.

\section{METHODS}

Recruitment

Children were recruited from the study area of the Bandim Health Project, which runs a health and demographic surveillance system in six districts of Bissau, the capital of Guinea-Bissau. The current population in these districts is around 102000 , which represents $30 \%$ of the inhabitants of the capital. All houses in the area are visited every month by a project representative, who registers new pregnancies and births. Furthermore, all children below 3 years of age are visited every three months to collect information on vita status and vaccination status.

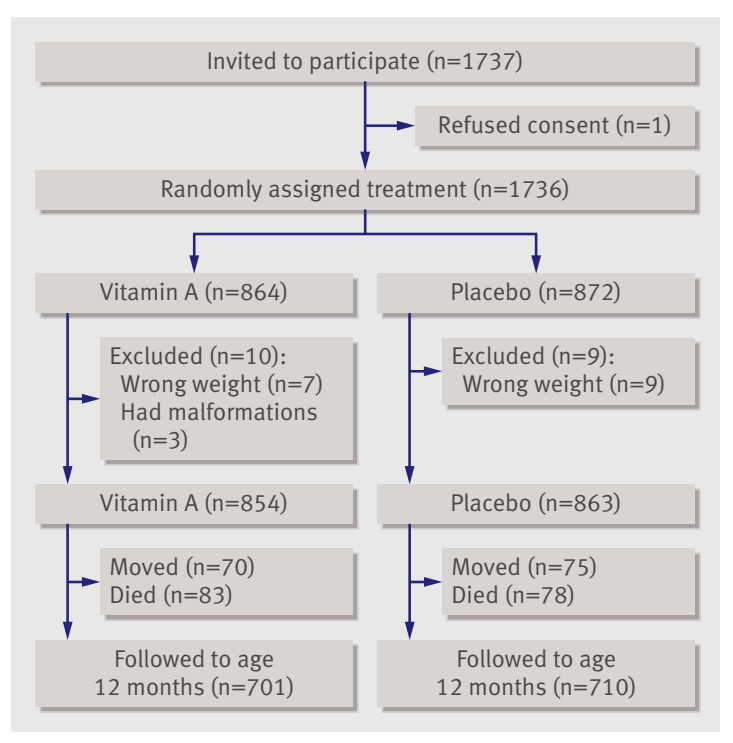

Fig 1| Trial profile 
Table 2 The effect of vitamin A supplementation at birth on infant mortality

\begin{tabular}{|c|c|c|c|c|c|}
\hline & \multicolumn{2}{|c|}{ Vitamin A supplementation } & \multicolumn{2}{|r|}{ Placebo } & \multirow[b]{2}{*}{$\begin{array}{c}\text { Mortality rate ratio } \\
(95 \% \mathrm{Cl})\end{array}$} \\
\hline & Total No & $\begin{array}{l}\text { Mortality per } 1000 \text { person years } \\
\text { (deaths/person years) }\end{array}$ & Total No & $\begin{array}{l}\text { Mortality per } 1000 \text { person years } \\
\text { (deaths/person years) }\end{array}$ & \\
\hline All children & 854 & $110(83 / 757)$ & 863 & $102(78 / 762)$ & $1.08(0.79$ to 1.47$)$ \\
\hline \multicolumn{6}{|l|}{ Stratified by BCG vaccination } \\
\hline Randomised to "early BCG" & 431 & $98(38 / 386)$ & 431 & $86(33 / 384)$ & $1.14(0.71$ to 1.84$)$ \\
\hline Randomised to "no early BCG" & 423 & $121(45 / 371)$ & 432 & $119(45 / 378)$ & $1.02(0.67$ to 1.56$)$ \\
\hline Interaction vitamin A supplementation and BCG & & & & & $P=0.73$ \\
\hline \multicolumn{6}{|l|}{ Stratified by sex } \\
\hline Boys & 362 & $86(28 / 325)$ & 394 & $118(41 / 349)$ & $0.74(0.45$ to 1.22$)$ \\
\hline Girls & 492 & $127(55 / 432)$ & 467 & $89(37 / 414)$ & $1.42(0.94$ to 2.15$)$ \\
\hline Interaction vitamin A supplementation and sex & & & & & $P=0.046$ \\
\hline
\end{tabular}

About 3000 children are born in the Bandim Health Project study area each year. The annual number of low birthweight infants identified in the Bandim Health Project study area, however, is only around 200-300. To follow a larger group of low birthweight children, in 2002 we initiated recruitment of low birthweight childrenfrom other areas of the capital at the maternity ward of the national hospital.

From 27 May 2005 to 31 January 2008, all low birthweight children born at the national hospital were offered participation in the two by two factorial trial, in which they were randomly assigned to early BCG (intervention group) or postponed BCG according to local practice (control group), as well as to either 25000 IU vitamin A (intervention group) or placebo (control group).

Neonates were identified when they were about to be discharged. They were investigated by a medical doctor (BMN), who ascertained that they had no severe malformations and that they were sufficiently well to be discharged according to local standards. The children were weighed on an electronic Seca scale (Seca $\mathrm{GmbH} \& \mathrm{Co}$, Hamburg, Germany). If the child weighed less than $2.5 \mathrm{~kg}$, the assistant at the maternity ward completed a questionnaire on background factors. Length was measured on a measuring board, and arm, head, and abdominal circumferences were measured with a TALC mid upper arm circumference tape (Teaching Aids at Low Cost, St Albans, UK) or a measuring tape. The Ballard score was used to assess gestational age.

The assistant explained the study to mothers or guardians in the local language (Creole) and provided a written explanation in the official language (Portuguese). If they wished their child to participate, the mother or guardian was asked to sign a consent form. Mothers or guardians who could not write their own name were asked to provide a fingerprint, which the assistant or the nurse certified.

\section{Intervention}

Once consent was provided, the mother drew an envelope from a bag. Each bag was prepared by the study supervisor and contained 48 envelopes; each envelope contained a lot name. Within each bag were 12 envelopes with lots marked "BCG 6," 12 marked "BCG 7,' 12 marked "no BCG 6," and 12 marked "no BCG 7." The numbers " 6 " and " 7 " indicated from which of two numbered bottles, " 6 " or " 7 ," the child should receive treatment (that is, either 25000 IU vitamin A or placebo). Twins were allocated the same treatment to prevent potential confusion regarding who had been vaccinated and supplemented. The envelopes were closed and non-transparent, making it impossible to identify the allocation before the envelopes were opened. The result of the randomisation was noted on the inclusion form and, furthermore, the lot name was stapled on the form.

Children randomly assigned to "early BCG" were vaccinated intradermally in the upper left deltoid region with $0.05 \mathrm{ml} \mathrm{BCG}$ vaccine (Statens Serum Institut, Copenhagen, Denmark). Children randomly allocated "no early BCG" did not receive a BCG vaccine. According to usual practice, mothers of children in the "no early BCG" group were told that their children should receive a BCG vaccination at a local health centre when the child had gained weight or when the child was due to receive the DTP vaccine and the oral polio vaccine at 6 weeks of age (all children should be offered

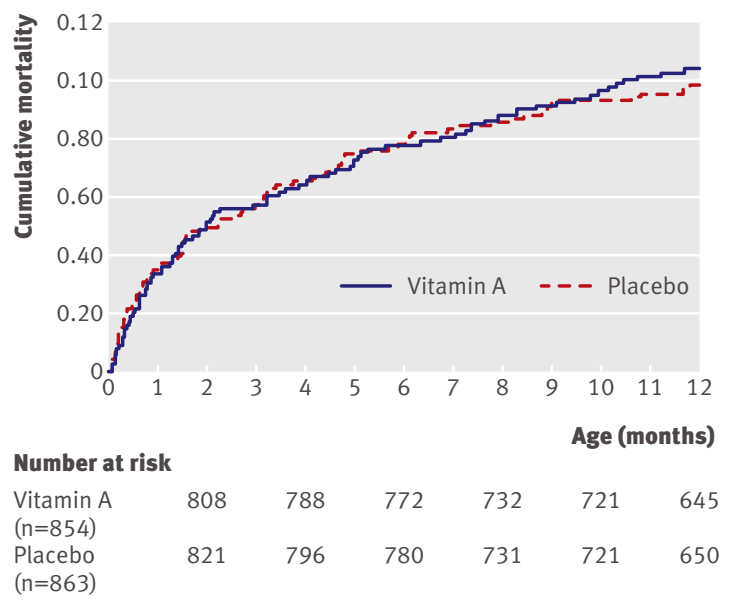

Fig 2 | Cumulative mortality during the first year of life for all children 
Table $3 \mid$ Mortality rate ratios according to weight at inclusion

\begin{tabular}{|c|c|c|c|c|c|c|c|c|c|c|}
\hline & \multirow[b]{2}{*}{ No (\%) } & \multicolumn{3}{|c|}{ All } & \multicolumn{3}{|c|}{ Boys } & \multicolumn{3}{|c|}{ Girls } \\
\hline & & $\begin{array}{c}\text { Vitamin } A \\
\text { supplementation } \\
(\mathrm{n}(\%))\end{array}$ & $\begin{array}{c}\text { Placebo } \\
\text { (n (\%)) }\end{array}$ & $\begin{array}{l}\text { Mortality rate } \\
\text { ratio }(95 \% \mathrm{Cl})\end{array}$ & $\begin{array}{c}\text { Vitamin } A \\
\text { supplementation } \\
(\mathrm{n}(\%))\end{array}$ & $\begin{array}{c}\text { Placebo } \\
\text { (n (\%)) }\end{array}$ & $\begin{array}{l}\text { Mortality rate } \\
\text { ratio }(95 \% \mathrm{Cl})\end{array}$ & $\begin{array}{c}\text { Vitamin } A \\
\text { supplementation } \\
(\mathrm{n}(\%))\end{array}$ & $\begin{array}{c}\text { Placebo } \\
\text { (n (\%)) }\end{array}$ & $\begin{array}{l}\text { Mortality rate } \\
\text { ratio }(95 \% \mathrm{Cl})\end{array}$ \\
\hline $2.0-2.49 \mathrm{~kg}$ & $1150(67)$ & $561(66)$ & $589(68)$ & $\begin{array}{c}1.15 \\
\text { (0.74 to } 1.80)\end{array}$ & $235(65)$ & $276(70)$ & $\begin{array}{c}0.58 \\
(0.27 \text { to } 1.25)\end{array}$ & $326(66)$ & $313(67)$ & $\begin{array}{c}1.74 \\
\text { (0.97 to } 3.15)\end{array}$ \\
\hline $1.5-1.99 \mathrm{~kg}$ & 449 (26) & 234 (27) & $215(25)$ & $\begin{array}{c}1.05 \\
\text { (0.60 to } 1.82)\end{array}$ & $103(28)$ & 99 (25) & $\begin{array}{c}0.73 \\
\text { (0.32 to } 1.68)\end{array}$ & $131(27)$ & $116(25)$ & $\begin{array}{c}1.46 \\
\text { (0.69 to } 3.08)\end{array}$ \\
\hline$<1.5 \mathrm{~kg}$ & $118(7)$ & $59(7)$ & $59(7)$ & $\begin{array}{c}0.89 \\
(0.41 \text { to } 1.91)\end{array}$ & $24(7)$ & $21(5)$ & $\begin{array}{c}0.90 \\
(0.29 \text { to } 2.76)\end{array}$ & $35(7)$ & $38(8)$ & $\begin{array}{c}0.83 \\
\text { (0.30 to } 2.27)\end{array}$ \\
\hline
\end{tabular}

*Adjusted for sex (except for sex stratified analyses) and randomisation to "early BCG" or "no early BCG."

oral polio vaccine at birth according to local practice). Concealing whether a child had received a BCG vaccination or not was not possible - the vast majority of vaccinated children develop a local reaction and subsequently a scar, and the vaccine was noted on the child's vaccination card. If we had used a placebo vaccine for the "no early BCG" group, some mothers might have erroneously believed that the child had received a BCG vaccine and they might not have sought BCG vaccination later on.

According to the result of the randomisation, children then received $0.5 \mathrm{ml}$ of oil from either bottle 6 or bottle 7 , which was slowly released into the mouth of the child with a sterile syringe by a nurse. The dark glass bottles used were prepared at Skanderborg Pharmacy, Denmark, and all contained 20 doses of $0.5 \mathrm{ml}$ of vegetable oil. Half of the bottles contained $25000 \mathrm{IU}$ vitamin A as retinyl palmitate and $10 \mathrm{IU}$ vitamin $\mathrm{E}$ per $0.5 \mathrm{ml}$ oil; the other half contained only $10 \mathrm{IU}$ vitamin E per $0.5 \mathrm{ml}$ oil. Apart from the bottle number, the vitamin A and placebo bottles looked alike. Small differences in the taste and colour of the contents were judged as unimportant owing to the recipients' age. The assistant and the nurse who were responsible for the randomisation procedures had no idea which bottles contained vitamin A or which had placebo when asked. The follow-up assistants were unaware of the allocated treatment, " 6 " or " 7 ," because they were not present during enrolment and the information was not transferred to the children's vaccination card or follow-up forms. The bottles were kept at $5^{\circ} \mathrm{C}$, and a fresh lot was prepared at least once a year. Under such circumstances, the stability of the retinyl palmitate is very high. ${ }^{19}$ The code of which treatment was in which bottle was kept at the pharmacy until 12 months after the last child was included. After the trial had ended, a pair of bottles (one bottle 6 and one bottle 7) were tested by Vitas Analytical Pharma Services in Oslo, Norway. The retinol concentration was $56879 \mathrm{IU} / \mathrm{ml}$ in one of the bottles (that is, $28440 \mathrm{IU}$ per $0.5 \mathrm{ml}$ ) and $0 \mathrm{IU} / \mathrm{ml}$ in the other bottle.

\section{Follow-up}

The children were visited at home within the first 3 days of enrolment and at 2, 6, and 12 months of age. To be able to follow-up the low birthweight children from outside the study area, we drove the mother and the newborn child home from the hospital. We then drew a simple map, registered global positioning system
(GPS) coordinates, and took a photo of the mother and the house to facilitate subsequent re-identification.

\section{Main outcomes}

The main outcome was infant mortality. Deaths were registered at each visit and the date of death recorded. When a death had been registered, it was followed up by a standard verbal autopsy conducted by a trained local physician at around three months after the death. The clinician assigned a probable diagnosis on the basis of the infant's history.

Routine vitamin A campaigns and vaccinations may have an impact on the overall results of an inter vention. $^{20}$ While this study was being conducted, there were seven national vitamin A campaigns: in November 2005, May and November 2006, June and December 2007, and June 2008 and January 2009. We collected information on vaccinations at the home visits. Apart from the home visits, vaccination data were also collected in case of hospitalisation at the national paediatric ward. Furthermore, we registered all vaccinations given daily at the local health centres in the Bandim Health Project study area, and the vaccination cards of low birthweight children living in the study area were inspected at the routine home visits every three months. A two dose measles vaccination trial that randomly assigned children to an early measles vaccine at age 4.5 months or to no early measles vaccine was in progress in the study area at the same time as the present trial. ${ }^{21}$ We had measles

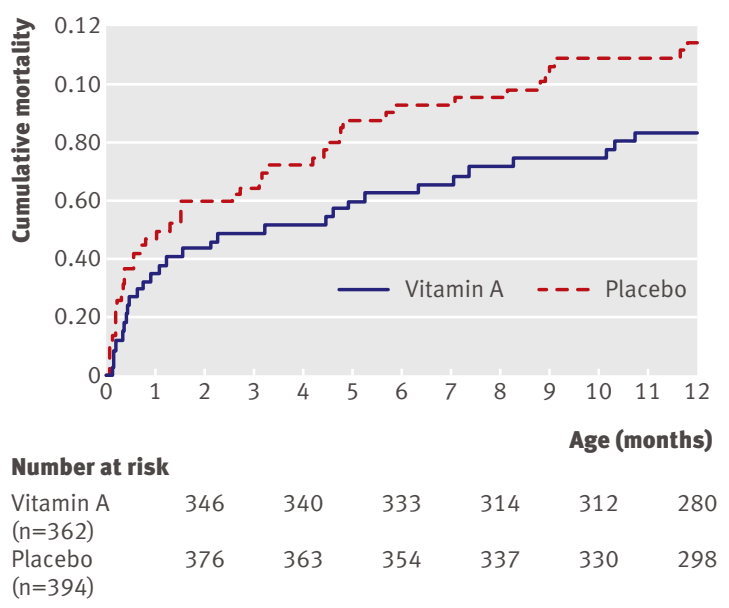

$\overline{\text { Fig } 3 \text { Cumulative mortality during the first year of life for boys }}$ 


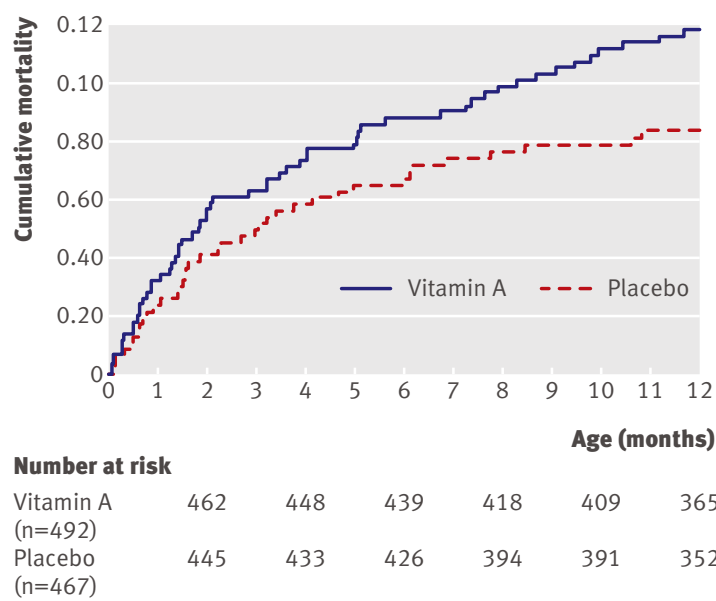

Fig $4 \mid$ Cumulative mortality during the first year of life for girls

vaccine information of these children at the exact date of the vaccination.

\section{Determinants suggested by previous studies}

Our previous trial of neonatal vitamin A supplementation in normal birthweight newborns in Guinea-Bissau showed unexpected interactions that we aimed to test in the present data set: (1) an interaction between vitamin A supplementation and season of administration (vitamin A supplementation had a better effect in the dry season from December to May than in the rainy season from June to November ${ }^{7}$ ); and (2) an interaction between vitamin A supplementation and subsequent DTP vaccination in girls (after DTP vaccination, neonatal vitamin A supplementation was associated with significantly increased mortality in girls $\left.{ }^{16}\right)$. We also tested the hypotheses that the effect of vitamin A supplementation at birth should be particularly beneficial during the first 48 hours of life ${ }^{22}$ and that the effect of vitamin A supplementation at birth varies by weight group.

\section{Combined analysis}

We integrated results of the present vitamin A supplementation trial in low birthweight neonates with those from our complementary trial in normal birthweight neonates to provide an overall estimate of the effect of providing neonatal vitamin A in Guinea-Bissau.

\section{Sample size calculations}

Assuming a confidence level of $95 \%$ and $80 \%$ power, and with an expected infant mortality between day 2 and 12 months of age of 25\% among low birthweight infants, we would need 720 low birthweight infants in each of the vitamin A and placebo groups to detect a $25 \%$ reduction in mortality associated with vitamin A supplementation. If we were to allow for a $10 \%$ loss to follow-up during the first two months (where there is high mortality), we would need 800 children in each group. Oral polio vaccine was missing in Guinea-Bissau during a short period of the trial, and 93 of the study participants did not receive oral polio vaccine at birth. Given that we had previously found that oral polio vaccine at birth has strong effects on mortality, ${ }^{23}$ we decided to increase the sample size to 1700 to make sure that we had enrolled 1600 children who had all received oral polio vaccine at birth.

Statistical analyses

All analyses were carried out in Stata 10.0.

\section{Main outcomes}

A priori, our intention was to study the effect of neonatal vitamin A supplementation on overall infant mortality. We also analysed the effect of vitamin A on survival from 0-3 months of age, when most previous trials have found a beneficial effect, and from 4-11 months of age. Accumulating evidence for sex differential effects of vitamin A supplementation ${ }^{7162425}$ made us hypothesise that vitamin A supplementation would be particularly beneficial for boys. ${ }^{25}$

We first analysed the data for interactions between vitamin A/placebo and "early BCG"/"no early BCG" allocation. No interaction was found. Owing to the design, all subsequent analyses of vitamin A effects were adjusted for "early BCG"/"no early BCG" allocation. All analyses were also adjusted for sex.

Cumulative mortality curves were calculated using the Kaplan-Meier estimate based on the date of death recorded at the first home visit after the death. Differences in mortality between groups were estimated using Cox proportional hazards models, with age in days as the time variable ${ }^{26}$; therefore, age was inherently controlled for in all analyses. Estimates are reported as mortality rate ratios (MRRs) with 95\% confidence intervals after follow-up to 12 months of age for infants who received vitamin A compared with those who received placebo. Person years at risk were calculated from enrolment of infants until they reached 12 months of age, moved, or died. The interdependency of outcomes within twin pairs or triplet groups was adjusted for by using robust standard errors. Tests for proportionality of hazard rates were computed using Schoenfeld's partial residuals and by visual inspection of Nelson-Aalen estimators.

Given that any subsequent administration of vitamin A could neutralise possible differential effects of the original intervention, we conducted an analysis in which we censored infants at the date of the first national vitamin A campaign after they had reached 6 months of age (and were thus eligible for the campaign). Hence, a child born in August 2005 would be censored at the first day of the national vitamin A campaign in May 2006, and so on.

\section{Determinants suggested by previous studies}

We conducted stratified analyses by season, vaccination status, age at enrolment, and weight group.

Owing to the special policy on BCG vaccination for low birthweight neonates - that is, that children should receive a BCG vaccination at a local health centre when the child had gained weight or when the child was due to receive the DTP vaccine and the oral polio vaccine at 6 weeks of age - there was large variation in the timing and sequence of vaccinations: the 


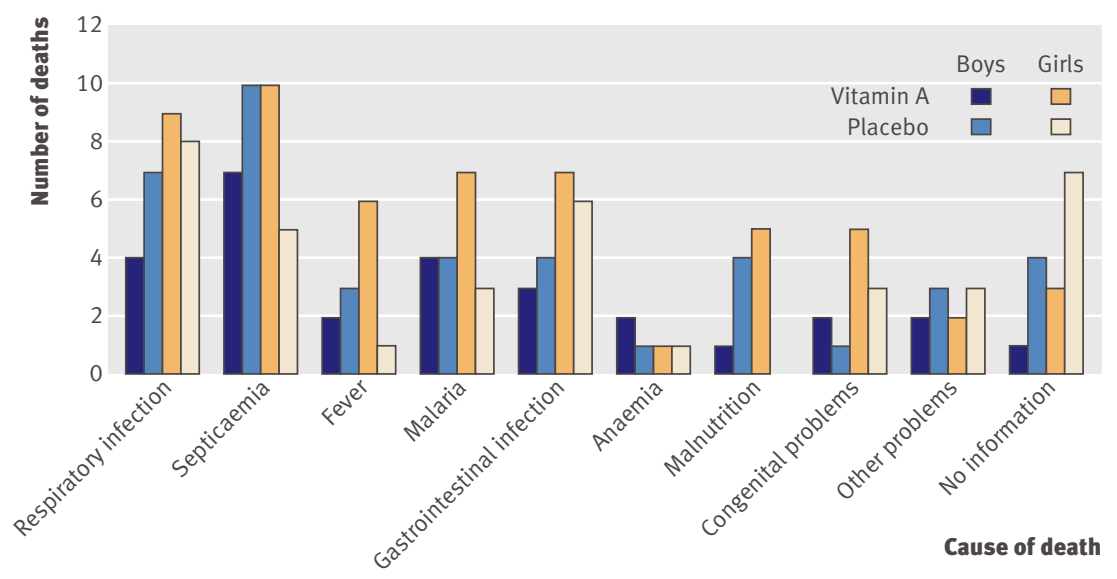

Fig 5 | Causes of deaths by intervention group and sex. The "Other problems" category includes AIDS related deaths, sudden death, tumours, encephalitis, and hepatitis

children in our study had 20 different vaccination statuses during 12 months' follow-up. Although many children had received the vaccines in the recommended sequence - that is, BCG before DTP vaccine - a lot of children also received vaccines out of sequence - that is, BCG with DTP vaccine or DTP vaccine before BCG. Deviations from the recommended schedule were more frequent in children outside the Bandim Health Project study area, where health centres are not covered by the Bandim Health Project staff. All analyses of vaccine status were, therefore, adjusted for the Bandim Health Project study area.

At 4 weeks of age, only $11 \%$ of the children in the control group had received the BCG vaccination; therefore, we undertook an analysis of the effect of vitamin A supplementation by randomisation to "early BCG" or "no early BCG" at birth in children between 0 and 4 weeks of age. The effect of vitamin A supplementation after DTP vaccination was studied by following up the children from the date of the first registered DTP vaccination until death, migration, measles vaccination, or 12 months of age, whichever came first.

The weight groups were defined as $<1.5 \mathrm{~kg}, 1.5-1.99$ $\mathrm{kg}$, and 2-2.49 kg.

Effect modification was analysed by investigating the homogeneity of the effect of vitamin A supplementation in the different categories of the suspected modifier by using the Wald test.

\section{Combined analysis}

The results of the present vitamin A supplementation trial in low birthweight neonates and those from the complementary trial in normal birthweight neonates were pooled using the "meta" command in Stata. A fixed effects model was used to pool the data because the heterogeneity tests indicated low degree of heterogeneity (all $\mathrm{P}>0.6)$.

\section{RESULTS}

A total of 1737 children were invited to participate in this trial, of whom 1736 (99.9\%) were randomly assigned to a study group: 864 to vitamin A supplementation and 872 to placebo (fig 1).

Children were enrolled on the basis of their weight at recruitment (less than $2.5 \mathrm{~kg}$ ); however, 16 children who weighed less than $2.5 \mathrm{~kg}$ at birth but gained weight and weighed $2.5 \mathrm{~kg}$ or more at enrolment were erroneously randomised. These children were subsequently excluded. Three children with malformations were enrolled in the study; all had been allocated to the vitamin A group. These infants were also excluded from the main analysis. Of the 19 children excluded in total, 10 had been randomly assigned to the vitamin A group (two children with malformations died, a boy and a girl) and 9 to the placebo group (none died).

A total of 1717 children were included in the final study population: 854 who were randomly assigned to vitamin A supplementation and 863 to placebo. There were 131 twin pairs and four groups of triplets in the trial. The baseline characteristics of the vitamin A supplementation and placebo groups are presented in table 1 .

\section{Main outcomes}

A total of 161 participants died between enrolment and their first birthday, which corresponds to a mortality rate of 106 deaths per 1000 person years, much lower than the anticipated rate of 250 deaths per 1000 person years. The mortality rate in infants who received vitamin A supplementation was 110 deaths per 1000 person years, compared with 102 deaths per 1000 person years among infants who received placebo (table 2).

Given that the trial was a two by two factorial design, we first analysed the data for interactions. No interaction was found between vitamin $\mathrm{A}$ /placebo and "early BCG"/"no early BCG" allocation $(\mathrm{P}=0.73$; table 2).

Our analysis controlled for randomisation to "early BCG" or "no early BCG" showed that vitamin A supplementation at birth was not associated with lower mortality than placebo (MRR $1.08,95 \%$ CI 0.79 to 1.47; fig 2). The result was unchanged when we excluded the 93 children who had not received oral polio vaccine at birth (MRR 1.13, 95\% CI 0.81 to 1.57).

Stratification by sex revealed a significant interaction between vitamin A supplementation and sex: vitamin A supplementation tended to be beneficial in boys (MRR $0.74,95 \%$ CI 0.45 to 1.22 ) but not in girls (MRR 1.42, 95\% CI 0.94 to $2.15 ; \mathrm{P}=0.046$ for interaction between vitamin A supplementation and sex; figs 3 and 4).

\section{Vitamin A campaigns}

Twelve deaths were excluded when we censored follow-up at the time of the first national vitamin A campaign after the child turned 6 months: six deaths in children who received vitamin A supplementation (two boys, four girls) and six deaths in children who received placebo (three boys, three girls). The overall MRR for vitamin A supplementation at birth after these exclusions was 1.08 (95\% CI 0.78 to 1.50$): 0.75$ (95\% CI 0.45 to 1.25$)$ in boys and 1.43 (95\% CI 0.93 to $2.21)$ in girls $(\mathrm{P}=0.06$ for interaction $)$. 
Table $4 \mid$ Mortality rate ratios according to vaccination status and weight at inclusion

\begin{tabular}{lccc} 
& \multicolumn{3}{c}{ Mortality rate ratio* $(95 \% \mathrm{Cl})$} \\
\cline { 2 - 4 } & & Bll & Goys \\
Age $0-4$ weeks & & & \\
\hline Allocated to "early BCG" & $1.28(0.50$ to 3.26$)$ & $1.67(0.46$ to 6.01$)$ & $0.92(0.23$ to 3.68$)$ \\
\hline Allocated to "no early BCG" & $0.98(0.48$ to 1.96$)$ & $0.56(0.20$ to 1.59$)$ & $1.64(0.60$ to 4.49$)$ \\
\hline Diphtheria-tetanus-pertussis vaccinated children & & \\
\hline All & $1.09(0.65$ to 1.82$)$ & $0.66(0.27$ to 1.59$)$ & $1.44(0.75$ to 2.78$)$ \\
\hline$\geq 2 \mathrm{~kg}$ & $1.49(0.72$ to 3.09$)$ & $0.57(0.14$ to 2.26$)$ & $2.35(0.90$ to 6.10$)$ \\
\hline$<2 \mathrm{~kg}$ & $0.80(0.39$ to 1.62$)$ & $0.70(0.23$ to 2.20$)$ & $0.87(0.34$ to 2.22$)$ \\
\hline
\end{tabular}

*Adjusted for Bandim Health Project study area, sex (except for sex stratified analyses), and randomisation to "early BCG" or "no early BCG" (analysis of diphtheria-tetanus-pertussis vaccinated children only).

\section{Cause of deaths}

According to the verbal autopsies, the higher number of deaths among girls who received vitamin A compared with girls who received placebo was due to fever, septicaemia, and malaria, as well as malnutrition (fig 5). There were fewer deaths from respiratory infections, septicaemia, and malnutrition in boys who received vitamin $\mathrm{A}$ than in boys who received placebo. No deaths during the first year of life were caused by accidents.

Determinants suggested by previous studies

Timing of supplementation

Vitamin A was administered within the first 48 hours of life to $878(51 \%)$ of the 1717 children in the final study population. The effect of vitamin A on mortality tended to be negative in children who received supplementation within the first 48 hours (MRR 1.30, 95\% CI 0.82 to 2.05$)$, but beneficial in children who received it later (MRR 0.88, 95\% CI 0.57 to $1.37 ; \mathrm{P}=0.23$ for interaction). The negative effect in children supplemented within the first 48 hours was seen particularly in girls: the mortality rate ratio was 2.27 (95\% CI 1.19 to 4.31$)$ for girls supplemented within 48 hours, compared with 0.94 (95\% CI 0.53 to 1.67) for girls supplemented later $(\mathrm{P}=0.046$ for interaction). The effect estimates were almost the same when we censored for vitamin A campaigns (data not shown).

\section{Anthropometric status}

Enrolment weight and age at supplementation were strongly associated because we only enrolled children about to be discharged from the maternity ward. The analysis of timing of vitamin A supplementation was, therefore, adjusted for weight group $(<1.5 \mathrm{~kg}$ (median age at enrolment nine days), $1.5-1.99 \mathrm{~kg}$ (median age at enrolment four days), $2.0-2.49 \mathrm{~kg}$ (median age at enrolment one day); table 3). The effect of vitamin A supplementation seemed best among the 59 (7\%) children who weighed less than $1.5 \mathrm{~kg}$ at enrolment (MRR 0.89, 95\% CI 0.41 to 1.91). Among the two thirds of children who weighed $2.0 \mathrm{~kg}$ or more, vitamin A supplementation was associated with a 15\% higher risk of death (MRR 1.15, 95\% CI 0.74 to 1.80 ). This trend was if anything more pronounced when we censored for vitamin A campaigns: in this situation the negative effect among girls weighing $2.0 \mathrm{~kg}$ or more was statistically significant (MRR 1.90, 95\% CI 1.00 to $3.61 ; \mathrm{P}=0.049)$.

\section{Season}

There was no interaction between vitamin A supplementation and season (data not shown).

\section{Vaccine status}

No strong differences in vitamin A supplementation effects according to BCG status were seen (table 4). Among children who had received the DTP vaccination, vitamin A supplementation tended to be associated with a slight beneficial effect in boys (MRR $0.66,95 \%$ CI 0.27 to 1.59 ), whereas the tendency was the opposite for girls (MRR 1.44, 95\% CI 0.75 to 2.78; $\mathrm{P}=0.16$ for interaction between vitamin A supplementation and sex). This differential effect was strongest among the two thirds of children who weighed $2.0 \mathrm{~kg}$ or more at enrolment (MRR 0.57, 95\% CI 0.14 to 2.26 for boys and MRR 2.35, 95\% CI 0.90 to 6.10 for girls; $\mathrm{P}=0.10$ for interaction between vitamin A supplementation and sex).

\section{Combined analysis}

When we combined the results from this trial in low birthweight infants and those from our previous trial in normal birthweight neonates, overall, neonatal vitamin A supplementation in Guinea-Bissau was not associated with lower mortality than placebo (MRR 1.08, 95\% CI 0.86 to 1.34). There was a significant sex differential effect (MRR 0.80, 95\% CI 0.58 to 1.10 in boys and MRR 1.41, 95\% CI 1.04 to 1.90 in girls; $\mathrm{P}=0.01$ for interaction between vitamin A supplementation and sex; table 5). The P values for homogeneity of vitamin A effects in the two trials were high (all $\mathrm{P}>0.60)$, reflecting the fact that the results of the two trials were similar.

\section{DISCUSSION}

\section{Main findings}

Vitamin A supplementation at birth in low birthweight neonates born at the national hospital in Bissau, Guinea-Bissau, did not reduce overall mortality. The overall result, an $8 \%$ increase in infant mortality, was almost exactly the same as that in our previous trial of normal birthweight infants. ${ }^{7}$ It has been suggested that the lack of beneficial effect of vitamin A supplementation at birth in our first study was because of the omission of low birthweight children from the trial. ${ }^{17} 18$ The present trial clearly shows that this is not the explanation. Although vitamin A supplementation may have a slight beneficial effect among children weighing less than $1.5 \mathrm{~kg}$, this group represented only $7 \%$ of all the low birthweight children and, therefore, this benefit had little effect on the overall effect estimate. Among the slightly heavier children, the effect of vitamin A supplementation was not beneficial.

As in the previous trial, we found a sex differential effect of vitamin A supplementation, with a tendency for a beneficial effect in boys but the opposite in girls. In the present trial, the interaction between vitamin $\mathrm{A}$ supplementation and sex was statistically significant.

A combined analysis of the two complementary Guinea-Bissau trials showed very homogeneous vitamin A effects among low birthweight and normal birthweight newborns. Although the results of this combined analysis 
Table 5 |Combined estimates of the effect of vitamin A supplementation on infant mortality in Guinea-Bissau

\begin{tabular}{|c|c|c|c|c|}
\hline & \multicolumn{3}{|c|}{ Mortality rate ratio $(95 \% \mathrm{Cl})$} & \multirow{2}{*}{$\begin{array}{l}\text { P for interaction } \\
\text { between vitamin } \\
\text { A and sex }\end{array}$} \\
\hline & All & Boys & Girls & \\
\hline \multicolumn{5}{|l|}{ Previous normal birthweight trial $^{6}$} \\
\hline All ages & 1.07 (0.79 to 1.44$)$ & $0.84(0.55$ to 1.27$)$ & $1.39(0.90$ to 2.14$)$ & 0.10 \\
\hline $0-3$ months & $1.00(0.65$ to 1.56$)$ & $0.94(0.52$ to 1.71$)$ & $1.09(0.56$ to 2.11$)$ & 0.76 \\
\hline 4-11 months & $1.13(0.75$ to 1.68$)$ & 0.74 (0.41 to 1.34$)$ & 1.67 (0.94 to 2.97$)$ & 0.05 \\
\hline \multicolumn{5}{|l|}{ Present low birthweight trial } \\
\hline All ages & $1.08(0.79$ to 1.47$)$ & $0.74(0.45$ to 1.22$)$ & $1.42(0.94$ to 2.15$)$ & 0.05 \\
\hline $0-3$ months & 1.03 (0.69 to 1.53$)$ & 0.75 (0.39 to 1.41$)$ & $1.29(0.78$ to 2.13$)$ & 0.18 \\
\hline 4-11 months & $1.16(0.69$ to 1.93$)$ & $0.73(0.34$ to 1.58$)$ & $1.74(0.84$ to 3.63$)$ & 0.11 \\
\hline \multicolumn{5}{|l|}{ Combined estimates (fixed effects model) } \\
\hline $0-11$ months & $1.08(0.87$ to 1.33$)$ & $0.80(0.58$ to 1.10$)$ & 1.41 (1.04 to 1.90$)$ & 0.01 \\
\hline $\mathrm{P}$ for homogeneity of vitamin A effects in the two trials & 0.97 & 0.70 & 0.94 & \\
\hline $0-3$ months & $1.02(0.76$ to 1.36$)$ & $0.85(0.55$ to 1.31$)$ & 1.21 (0.81 to 1.81$)$ & 0.24 \\
\hline $\mathrm{P}$ for homogeneity of vitamin A effects in the two trials & 0.92 & 0.61 & 0.69 & \\
\hline 4-11 months & 1.14 (0.83 to 1.57$)$ & $0.74(0.46$ to 1.18$)$ & 1.70 (1.08 to 2.67$)$ & 0.01 \\
\hline P for homogeneity of vitamin A effects in the two trials & 0.94 & 0.98 & 0.93 & \\
\hline
\end{tabular}

should be interpreted with caution, they do point towards a significant sex differential effect of vitamin A supplementation and a significant negative effect of neonatal vitamin A supplementation in girls.

\section{Determinants of vitamin A effect}

Sex

The present neonatal vitamin A supplementation trial among low birthweight infants gave surprisingly similar results to those in our first neonatal vitamin A supplementation trial in normal birthweight infants. The combined estimate of the effect of vitamin A supplementation on mortality in Guinea-Bissau was 0.80 in boys and 1.41 in girls. Whereas a mortality reduction of $20 \%$ in boys is by no means a small achievement, the $41 \%$ significantly increased mortality in girls is worrying. Although the combined analysis of the two separate trials cannot be considered equivalent to a single trial enrolling both low birthweight and normal birthweight neonates and randomising them to the same type of treatment at the same time, it seems clear that girls in Guinea-Bissau do not benefit from neonatal vitamin A supplementation.

The very first trial of neonatal vitamin A supplementation from Indonesia found a borderline significant sex differential effect ${ }^{2}$; in the Indian trial, the effect of vitamin A supplementation was only significantly beneficial in boys. ${ }^{3}$ So far, the Bangladeshi trial, which had low coverage for the DTP vaccine, is the only one that has reported a beneficial effect of vitamin A supplementation on mortality in girls. ${ }^{4}$

Sex differences in the response to vitamin A supplementation could be due to initial differences in vitamin A status. In fact, two studies have shown that boys have lower retinol levels in their cord blood than do girls. ${ }^{2728}$ This finding, however, would not explain a negative effect in girls. We have proposed that the negative effect of vitamin A and other micronutrients like iron and zinc on mortality in infant girls may be the result of a negative interaction between immunomodulating micronutrients and the DTP vaccine, which has been associated in observational studies with increased female mortality. ${ }^{29}$ We need sex stratified data from the trials in Zimbabwe ${ }^{56}$ and $\mathrm{Nepal}^{8}$ to assess whether the sex differences in response to neonatal vitamin A supplementation are a more general phenomenon or related to DTP vaccine coverage.

It is worth emphasising that trials of interventions rarely examine whether the effect is the same for girls and boys. In the two trials of vitamin A supplementation at birth that we have conducted, the overall "no effect" mortality rate ratio estimate encompasses a negative effect for girls and a potentially beneficial effect for boys. By not analysing effects by sex, we may miss important beneficial effects and also potentially cause harm. Trials in low income countries with high infant and child mortality should always examine the intervention for potential sex differential effects.

\section{Vaccine status}

As in our previous study, the sex differential effect of vitamin A supplementation tended to be stronger after DTP vaccination. The present cohort was small, however, and the overall influence of DTP vaccination on the effect of vitamin A on mortality was not statistically significant. Among girls who weighed $2.0 \mathrm{~kg}$ or more at enrolment, those who received vitamin A supplementation and the DTP vaccine had twofold higher mortality than those who received the placebo and the DTP vaccine, as was found in previous studies of the interaction between vitamin A supplementation and the DTP vaccine. ${ }^{1630-33}$

Mortality was much higher in the small group of children who weighed less than $2.0 \mathrm{~kg}$ at enrolment. In this group, there was no differential effect of vitamin A supplementation among children who had received the DTP vaccination and those who had not. Presumably many other "competing" causes of death exist in this 


\section{WHAT IS ALREADY KNOWN ON THIS TOPIC}

Six trials of neonatal vitamin A supplementation have shown divergent results with respect to the impact of supplementation on mortality

Three of the four trials conducted in Asia found a significant beneficial effect of neonatal vitamin A supplementation, whereas both of the two trials conducted in Africa found no beneficial effect

The lack of beneficial effect in the African trial from Guinea-Bissau could be to the result of exclusion of low birthweight neonates

\section{WHAT THIS STUDY ADDS}

Neonatal vitamin A supplementation had no overall effect on infant mortality among low birthweight neonates in Guinea-Bissau

The effect of vitamin A differed significantly by sex: supplementation tended to be beneficial in boys but not in girls

The significant sex differential effect of vitamin A supplementation remained when the data from this trial were combined with the complementary trial conducted among normal birthweight neonates in Guinea-Bissau for example, maternal night blindness seems more prevalent in the Asian trials than in the African trials, where virtually no mothers experienced night blindness. ${ }^{12}$ Also, in our trial in Guinea-Bissau, only $9 \%$ of normal birthweight infants had low vitamin A levels at age 4 months. ${ }^{15}$ However, children in the Indonesian trial likewise had a good vitamin A status, but a very good effect of vitamin A on mortality was reported. ${ }^{2}$ Also, the subgroup of 4495 HIV positive women in the Zimbabwean trial presumably had vitamin A deficiency, yet vitamin A had no beneficial effect in that group. ${ }^{6}$ Furthermore, vitamin A supplementation had a significant negative effect in the large majority of the children who were HIV negative. Hence, although vitamin A supplementation certainly prevents and treats vitamin A deficiency, it seems that other environmental factors may modify the effect, making it impossible to predict outcome on the basis of the pre-existing degree of vitamin A deficiency alone.

We propose that the divergent results in all these trials may be explained by differences in vaccination intensity. ${ }^{1213}$ In our experience, neonatal vitamin A supplementation may have a negative effect on girls once they receive DTP vaccine. ${ }^{16}$ If the coverage for the DTP vaccine is high, the survival curves of children who receive vitamin $\mathrm{A}$ and those who get placebo should cross over once they start receiving DTP vaccine at around 2 months of age. This pattern is seen in Guinea-Bissau $^{7}$ and in Zimbabwe, ${ }^{5}$ which both had high vaccination coverage. ${ }^{12}$ Vaccination coverage was presumably lower in the Asian trials. ${ }^{12}$ Hence, existing data are compatible with the hypothesis that early DTP vaccination might interfere with the beneficial effect of neonatal vitamin A supplementation.

Importantly, a negative interaction of this sort would have the largest impact in settings where there is high mortality throughout infancy. In the Asian trials, nearly all deaths occurred in the first 1-2 months of life; as such, mortality would not be affected by a negative interaction between vitamin A supplementation and DTP vaccine, which is only administered around 2 months of age. In contrast, the African trials recorded high mortality throughout the 12-24 months of follow-up. "High neonatal mortality combined with little mortality in the subsequent months" may be better than "South Asia" as an indicator of populations in which neonatal vitamin A supplementation may be beneficial. ${ }^{12}$

\section{Comparison with other studies}

Seven trials, including this trial, have studied the effect of neonatal vitamin A supplementation on mortality. Three of the four trials from Asia found a beneficial effect, whereas the three trials from Africa found no beneficial effect.

It has been proposed that these divergent results could be due to differences in the prevalence of vitamin A deficiency in the two regions. ${ }^{17}$ Direct comparisons between these trials, however, are hampered by the fact that the trials collected different indicators of vitamin A deficiency. Some results suggest that there was a better effect of supplementation in areas with vitamin A deficiency; 
Since the research was conducted, author Bitiguida Mutna Napirna has died.

Contributors: CSB, ARoth, MY, ARodrigues, HW, and PA designed the study. CSB, ARoth, and PA initiated the study. ABF, BMN, BRD, and KRL were responsible for the recruitment and follow-up of participants. CSB was responsible for the statistical analysis, with assistance from $\mathrm{HR}$ and PA. CSB wrote the first draft of the paper. All authors contributed to and approved the final version of the paper. CSB was the chief investigator and is the guarantor.

Funding: The study was funded by the EU (ICA4-CT-2002-10053), the Danish Medical Research Council, University of Copenhagen, March of Dimes, and the Ville Heise Foundation. The Bandim Health Project received support from DANIDA and the Danish National Research Foundation. PA holds a research professorship grant from the Novo Nordisk Foundation. The funding agencies had no role in the study design, in the data collection, analysis, and interpretation, or in the writing of the report.

Competing interests: All authors have completed the Unified Competing Interest form at www.icmje.org/coi_disclosure.pdf (available on request from the corresponding author) and declare (1) No financial support for the submitted work from anyone other than their employer; (2) No financial relationships with commercial entities that might have an interest in the submitted work; (3) No spouses, partners, or children with relationships with commercial entities that might have an interest in the submitted work; (4) No non-financial interests that may be relevant to the submitted work.

Ethical approval: The protocol was approved by the Danish Central Ethics Committee and the Guinean Ministry of Health's Research Coordination Committee.

Data sharing: No additional data available.

1 Fawzi WW, Chalmers TC, Herrera MG, Mosteller F. Vitamin A supplementation and child mortality: a meta-analysis. JAMA 1993;269:898-903.

2 Humphrey JH, Agoestina T, Wu L, Usman A, Nurachim M, Subardja D, et al. Impact of neonatal vitamin A supplementation on infant morbidity and mortality. J Pediatr 1996;128:489-96.

3 Rahmathullah L, Tielsch JM, Thulasiraj RD, Katz J, Coles C, Devi S, et al. Impact of supplementing newborn infants with vitamin $A$ on early infant mortality: community based randomised trial in southern India. BMJ 2003;327:254.

4 Klemm RD, Labrique AB, Christian P, Rashid M, Shamim AA, Katz J, et al. Newborn vitamin A supplementation reduced infant mortality in rural Bangladesh. Pediatrics 2008;122:e242-e50.

5 Malaba LC, Iliff PJ, Nathoo KJ, Marinda E, Moulton LH, Zijenah LS, et al. Effect of postpartum maternal or neonatal vitamin A supplementation on infant mortality among infants born to HIVnegative mothers in Zimbabwe. Am J Clin Nutr 2005;81:454-60.

6 Humphrey JH, Iliff PJ, Marinda ET, Mutasa K, Moulton LH, Chidawanyika $\mathrm{H}$, et al. Effects of a single large dose of vitamin $\mathrm{A}$, given during the postpartum period to HIV-positive women and their infants, on child HIV infection, HIV-free survival, and mortality. J Infect Dis 2006;193:860-71.

7 Benn CS, Diness BR, Roth A, Nante E, Fisker AB, Lisse IM, et al. Effect of 50000 IU vitamin A given with BCG vaccine on mortality in infants in Guinea-Bissau: randomised placebo controlled trial. BMJ 2008;336:1416-20.

8 West KP Jr, Katz J, Shrestha SR, LeClerq SC, Khatry SK, Pradhan EK, et al. Mortality of infants $<6$ mo of age supplemented with vitamin A: a randomized, double-masked trial in Nepal. Am J Clin Nutr 1995;62:143-8

9 Abrams SA, Hilmers DC. Postnatal vitamin A supplementation in developing countries: an intervention whose time has come? Pediatrics 2008;122:180-1.

10 Gogia S, Sachdev HS. Neonatal vitamin A supplementation for prevention of mortality and morbidity in infancy: systematic review of randomised controlled trials. BMJ 2009;338:b919.

11 Sachdev HP. Neonatal vitamin A supplementation and infant survival in Asia. Lancet 2008;371:1746.

12 Benn CS, Whittle H, Fisker A, Aaby P. Neonatal vitamin A supplementation in South Asia: rapid implementation or understanding the variation? [electronic response to Tielsch JM Vitamin A supplements in newborns and child survival] $B M$ J
2008; http://www.bmj.com/cgi/eletters/336/7658/ 1385\#198676.

13 Benn CS, Fisker AB, Jørgensen MJ, Aaby P. Conflicting evidence for neonatal vitamin A supplementation. Vaccine 2008;26:4111-2.

14 WHO Global Database on Vitamin A deficiency. Global prevalence of vitamin A deficiency in populations at risk 1995-2005. http:// whqlibdoc.who.int/publications/2009/9789241598019_eng.pdf.

15 Fisker AB, Lisse IM, Aaby P, Erhardt J, Rodrigues A, Bibby BM, et al. Impact of neonatal vitamin $A$ supplementation with $B C G$ vaccine on vitamin A status at 6 weeks and 4 months of age. Am J Clin Nutr 2007;86:1032-9.

16 Benn CS, Rodrigues A, Yazdanbakhsh M, Fisker AB, Ravn H, Whittle $\mathrm{H}$, et al. The effect of high-dose vitamin A supplementation administered with BCG vaccine at birth may be modified by subsequent DTP vaccination. Vaccine 2009;27:2891-8.

17 Tielsch JM. Vitamin A supplements in newborns and child survival. BMJ 2008;336:1385-6.

18 Tielsch JM, Klemm R, West KP, Katz J, Humphrey J, Christian P, et al. Newborn vitamin A dosing and infant survival. Sight and Life Magazine

2008;2:22-6. http://www.sightandlife.org/joomla15/images/ stories/pageimages/content/News/ newborn_vitamin_a_dosing_and_early_infant_survival.pdf.

19 WHO/UNICEF/IVACG. Vitamin A supplements: a guide to their use in the treatment and prevention of vitamin A deficiency and xerophthalmia. 2nd ed. World Health Organization, 1997.

20 Aaby P, Jensen H, Samb B, Cisse B, Sodeman M, Jakobsen M, et al. Differences in female-male mortality after high-titre measles vaccine and association with subsequent vaccination with diphtheriatetanus-pertussis and inactivated poliovirus: reanalysis of West African studies. Lancet 2003;361:2183-88.

21 Martins CL, Garly ML, Balé C, Rodrigues A, Ravn H, Whittle HC, et al. Protective efficacy of standard Edmonston-Zagreb measles vaccination in infants aged 4.5 months: interim analysis of a randomised clinical trial. BMJ 2008;337:a661.

22 Report of the WHO technical consultation on neonatal vitamin A supplementation research priorities. Geneva, Switzerland, 4-5 December 2008. http://www.who.int/nutrition/publications/ micronutrients/vitamin_a_deficieny/NVAS_report.pdf.

23 Benn CS, Fisker AB, Rodrigues A, Ravn H, Sartono E, Whittle H, et al. Sex-differential effect on infant mortality of oral polio vaccine administered with BCG at birth in Guinea-Bissau. A natural experiment. PLOS ONE 2008;3:e4056.

24 Benn CS, Martins C, Rodrigues A, Jensen H, Lisse IM, Aaby P. Randomised study of the impact of different doses of vitamin $A$ on childhood morbidity and mortality. BMJ 2005;331:1428-32.

25 Benn CS, Fisker AB, Diness BR, Aaby P. Sex-differential effects of neonatal vitamin A supplementation on mortality? J Infect Dis 2006;194:719.

26 Cox DR, Oakes D. Analysis of survival data. Chapman \& Hall, 1984.

27 Yassai MB, Malek F. Newborns vitamin A in relation to sex and birth weight. J Trop Pediatr 1989;35:247-9.

28 Tolba AM, Hewedy FM, al-Senaidy AM, al-Othman AA. Neonates' vitamin A status in relation to birth weight, gestational age, and sex.J Trop Pediatr 1998;44:174-7.

29 Benn CS, Lund S, Fisker A, Jørgensen MJ, Aaby P. Should infant girls receive micronutrient supplementation? Int J Epidemiol 2009;38:586-90.

30 Benn CS, Martins C, Rodrigues A, Ravn H, Fisker AB, Christoffersen D, et al. The effect of vitamin $A$ supplementation administered with missing vaccines during national immunisation days in GuineaBissau. Int J Epidemiol 2009;38:304-11.

31 Benn CS, Aaby P, Nielsen J, Binka FN, Ross DA. Does vitamin A supplementation interact with routine vaccinations? An analysis of the Ghana Vitamin A Supplementation Trial. Am J Clin Nutr 2009;90:629-39.

32 Newton S, Cousens S, Owusu-Agyei S, Filteau S, Stanley C, Linsell L, et al. Vitamin A supplementation does not affect infants' immune responses to polio and tetanus vaccines. J Nutr 2005;135:2669-73.

33 Newton S, Owusu-Agyei S, Filteau S, Gyan T, Kirkwood BR. Vitamin A supplements are well tolerated with the pentavalent vaccine. Vaccine 2008;26:6608-13.

34 Darlow BA, Graham PJ. Vitamin A supplementation to prevent mortality and short and long-term morbidity in very low birthweight infants. Cochrane Database Syst Rev 2007;(4):CD000501.

Accepted: 18 February 2010 